\title{
A realidade da família monoparental chefiada pelo homem dentro do Programa Bolsa Família do Governo Federal na cidade de Manaus ${ }^{1}$
}

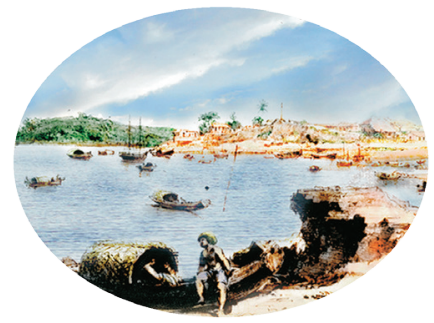

Kalleandra Muniqui Ramos Antela* Cristiane Manique Barreto**

\section{Resumo}

Nos anos 80 acentuam-se as políticas públicas e os programas sociais no Brasil na perspectiva de gênero. Dentro deste contexto, este trabalho discutirá sobre a questão de gênero que envolve a titularidade do pagamento do benefício concernente ao Programa Bolsa Família na cidade de Manaus - Amazonas, no qual realizamos uma pesquisa na Central do Programa. Procuramos conhecer parte da realidade da família monoparental chefiada pelo homem cuja titular do benefício do Programa Bolsa Família era a ex esposa, identificando o porquê do abandono da cônjuge, detectando processos de mudanças e permanências nas relações de gênero contemporâneas.

Palavras-chave: Gênero; políticas públicas; programas de transferência de renda; família.

\begin{abstract}
In the 80 are increasing public policies and social programs in Brazil from the perspective of gender, in this context this work discuss the issue of gender that involves the payment of the benefit of ownership regarding the Bolsa Familia Program in the city of Manaus - Amazonas in which we conducted a search in the Central program. We know the reality of single-parent families headed by men whose

\footnotetext{
* Assistente social graduada pela Faculdade Salesiana Dom Bosco (FSDB), Manaus - Amazonas.

** Mestre em História pela Universidade Federal do Rio Grande so Sul (UFRGS), professora da Faculdade Salesiana Dom Bosco (FSDB) e do Centro Universitário do Norte (Uninorte).
} 
holder the benefit of the Family Scholarship Program was the former wife, identifying the reason of the abandonment of spouse, procedures for detecting changes and stay contemporary in gender relations.

Keywords: Gender; public policies; programs; transfer income; family.

\section{Introdução}

Fala-se e ouve-se muito no meio acadêmico da mulher mãe e pobre, ficando no esquecimento o sujeito pai e pobre. Portanto, conhecer e detectar na atualidade como vem sucedendo o desempenhar dos papéis de homens e mulheres contextualizando as políticas públicas em especial as assistenciais na forma de transferência de renda, sinalizando o pagamento do benefício Bolsa Família é de importante valia para elaboração de políticas, projetos e programas futuros.

Em torno deste programa de transferência de renda rodeiam problemas de várias ordens, no entanto, trataremos somente de um deles referente a titularidade do beneficio ser concedido às mulheres onde há o abandono desta de seus lares, muitas vezes deixando o marido e filhos sem o benefício, estando ainda na condição de titular no pagamento do programa supracitado.

Surge um novo modelo familiar, dado por esse abandono, que busca novas formas de intervenção profissional na relação de gênero que os novos tempos colocam, no qual este trabalho buscará um pouco desvelar.

\section{As relações de gênero nas camadas populares de nossa sociedade}

O gênero, é uma categoria de análise que envolve o relacionamento de homens e mulheres, e é construído e fomentado com base em símbolos, normas e instituições que definem modelos de masculinidade e feminilidade e padrões de comportamento aceitáveis ou não para ambos. O gênero delimita campos de atuação para cada sexo. $\mathrm{Na}$ figura da mulher ainda persiste a ideia de fragilidade, de reprodutora, de ente responsável pelos filhos e isso repercute na elaboração de leis, políticas públicas, projetos sociais e suas formas de aplicação.

Quanto à subjetividade de cada sujeito, podemos dizer que é constituída nas relações sociais, que envolvem historicamente relações de gênero, classe, etnia e geração, neste sentido o gênero é uma construção social sobreposta a 
um corpo sexuado. É uma forma primeira de significação de poder (SCOTT, 1989: apud Ministério da Saúde, 2004).

Nesse pressuposto, os símbolos, normas e instituições, social e cultural exercem formas de pressão implicitamente impostas a homens e mulheres nos seus comportamentos e condutas do cotidiano que os envolve, seja no trabalho, no lar, na criação dos filhos, etc., isto é, repassado de forma cultural desde a infância no âmbito da família, na escola, no ato de brincar, nos meios de comunicação, através das construções sociais. As práticas sexuais dos papéis assim são estipulados. Não cumpri-los pode ser categorizado num desvio social, haja vista os atributos dos papéis estarem carregados de valores, que podem alterar-se com o passar dos tempos, pois a realidade é dinâmica, logo gênero pode ser considerado uma relação social que atribui papéis a serem desempenhados pelos dois sexos e que podem variar até mesmo entre as categorias: homem/mulher, homem/homem e mulher/mulher, dependendo de cada situação, se levado em conta os estratos sociais.

Quando Hera (1995) explica a condição de gênero, a autora aborda o "ser" como elemento da existência que envolve cada sexo; existo mulher ou existo homem. Relaciona as leis, políticas e práticas sociais como forma de suprir as desigualdades e desequilíbrios constituídos no bojo das relações de gênero.

Gênero se refere ao conjunto de relações, atributos, papéis, crenças e atitudes que definem o que significa ser homem ou ser mulher. $\mathrm{Na}$ maioria das sociedades, as relações de gênero são desiguais os desequilíbrios de gênero se refletem nas leis, políticas e práticas sociais, assim como nas identidades, atitudes e comportamentos das pessoas. As desigualdades de gênero tendem a aprofundar outras desigualdades sociais e a descriminação de classe, raça, casta, idade, orientação sexual, etnia, deficiência, língua ou religião, dentre outras (HERA, 1995: apud Ministério da Saúde, 2004).

Como advoga Louro, (2007, p. 11): “As identidades de gênero e sexuais são, portanto, compostas e definidas pelas relações sociais, e elas são moldadas pelas redes de poder de uma sociedade". 
Diante do exposto na visão burguesa o papel do homem esta relacionado às afirmações que Rodrigues (1992) faz sobre: “... a posição de pai que (sic) implica determinadas obrigações para com os filhos, como a de garantir-lhes a alimentação, moradia, proteção etc. Também implica certos direitos, como o de ser obedecido e respeitado (p. 135). Afirma ainda que os papéis: “... designa o modelo de comportamento que caracteriza o lugar do indivíduo no grupo ou organização" (p. 137). Em outras palavras cabe ao homem as tarefas na esfera privada para prover a família.

Considerando as relações de gênero como elemento não uniforme dentro das camadas sociais da nossa sociedade, no qual o fator econômico, cultural, temporal e de espaço são causadores de influências nos relacionamentos de homens e mulheres, distinguindo-os, a história mostra que há procedimentos dispares nas atribuições e no desempenhar dos papéis que cada classe social vivencia em seu ambiente familiar.

A cultura impõe certos comportamentos, normas e deveres para homens e mulheres, porém a realidade de cada categoria se diferenciam, pois nem sempre o homem é provedor do lar, proeminente nas classes populares sendo que a mulher e o homem pobre geralmente dividem as despesas. Há de se considerar que a falta do pleno emprego torna-se relevante para um homem desempenhar ou não seu papel de provedor.

Contudo, há diferença dos papéis até mesmo entre as mulheres ressaltando principalmente a condição de classe, como exemplo cultural utilizamos o casamento e a maternidade que conforme Louro: “... eram efetivamente constituídos como a verdadeira carreira feminina. Tudo que levasse as mulheres a se afastarem desse caminho seria percebido como um desvio de norma" (2007, p. 454). Em nosso País no período da Belle Époque (1890-1920) os moldes comportamentais dos papéis entre homens e mulheres foram configurando o modelo "adequado" para cada um, embora como atesta Soihet, (1997), as diferenças comportamentais começam no mesmo sexo de classes diferentes.

Apesar da existência de muitas semelhanças entre mulheres de classes sociais diferentes, aquelas das camadas populares possuíam características próprias, padrões específicos, ligados às suas condições concretas de existência. Como era 
grande sua participação no "mundo do trabalho", embora mantidas numa posição subalterna, as mulheres populares, em grande parte, não se adaptavam às características dadas como universais ao sexo feminino: submissão, recato, delicadeza, fragilidade. Eram mulheres que trabalhavam e muito, em sua maioria não eram formalmente casadas, brigavam na rua, pronunciavam palavrões, fugindo, em grande escala, aos estereótipos atribuídos ao sexo frágil (p. 367).

Submissão, recato, delicadeza moldavam o comportamento e o papel da mulher burguesa e, fugindo a tais características estava a mulher pobre. Seus relacionamentos e sua vida demonstravam que ela deixava completamente de lado a figura do sexo frágil, uma vez que a condição econômica ditava suas normas de condutas. Não havia homogeneidade nem entres os homens, na atualidade o Ministério para as Crianças e os Assuntos da Família da Noruega ${ }^{2}$ esclarece: “Os homens não constituem um grupo uniforme, nem é possível falar de um único papel masculino. A masculinidade nem sempre é equivalente ao poder. Os homens levam diversos tipos de vida diferentes e têm interesses muito diversificados", e isso ocorre a várias décadas.

Como gênero é a atribuição dos papéis a serem desempenhados por homens e mulheres, as desigualdades e desequilíbrios relacionando a eles começam nos estratos sociais, no exercer dos papéis dentro dos lares, nas relações de homens e mulheres pobres e ricos, casados ou unidos por laços matrimoniais estáveis ou instáveis.

O homem pobre não estava longe da realidade de classe que as mulheres pobres também comportavam. O homem provedor que não deixa nada faltar em casa e para família ficava mais a critério do homem rico/burguês.

Para entendermos hoje os padrões da execução ou não do papel estipulado para o masculino, em particular do homem, que se encontra na condição de pobreza, a Soihet (1997), num artigo sobre os anos da Belle Époque (1890-1920) afirma:

O homem pobre, por suas condições de vida, estava longe de poder assumir o papel de mantenedor da família previsto pela ideologia dominante, tampouco o papel de dominador, típico desses padrões. Ele sofria a influência dos referidos 
padrões culturais e, na medida em que sua prática de vida revelava uma situação bem diversa em termos de resistência de sua companheira a seus laivos de tirania, era acometido de insegurança. A violência surgia, assim, de sua incapacidade de exercer o poder irrestrito sobre a mulher, sendo antes uma demonstração de fraqueza e impotência do que de força e poder (p. 370).

O sofrimento com a situação econômica, fruto da falta de emprego para alguns, e para os que trabalhavam os seus baixos salários que não supriam totalmente o sustento do lar, outorgava uma posição social no meio da família aos homens pobres diferente da que os homens das outras classes sociais vivenciavam, estes, sim, eram os provedores, aqueles eram os ajudadores - ou não - no orçamento da casa e dos filhos junto à companheira, consoante Soihet (1997, p. 370): “... desprovidos de poder e de autoridade no espaço público no trabalho e na política -, seria assegurado o exercício no espaço privado, ou seja, na casa e sobre a família". Quanto à violência, esta pode ser o resultado do sofrimento das imposições culturais a sua figura de homem, pois havia uma cobrança social que muitas vezes os afligiam, e eram vítimas de preconceitos - a exemplo das mulheres pobres que trabalhavam fora.

Atualmente os homens reconhecem publicamente que a masculinidade da forma que foi imposta os aprisionava como nos desvela Hamawi (1995, p. 9): "Efetivamente, muitos de nós criticamos o modelo masculino sob o qual fomos educados. Modelo ao qual já não nos conformamos (no duplo sentido de formar/adequar) e que começa a nos sufocar".

No tocante à mulher, atuar na vida pública sempre propiciou autonomia no relacionamento, isto rendeu no século XIX e começo do XX, críticas que Rago, descreve:

Muitos acreditavam, ao lado dos teóricos e economistas ingleses e franceses, que o trabalho da mulher fora de casa destruiria a família, tornaria os laços familiares mais frouxos e debilitaria a raça, pois as crianças cresceriam mais soltas, sem a constante vigilância das mães. As mulheres deixariam de ser mães dedicadas e esposas carinhosas, se trabalhassem fora do lar; além do que um bom número delas deixaria de se interessar pelo casamento e pela maternidade (2007, p. 585). 
É explicito afirmar que em nossa sociedade foi adotado um modelo de masculinidade e feminilidade burguês para reger normas, instituições e comportamentos, cabendo ao homem o domínio do poder, e a mulher à subordinação, o âmbito privado do lar, a fidelidade ao marido e a família por longos anos, todavia, esta imposição encontra na realidade inúmeras situações, pois na existência efetiva tudo é mais complexo, as relações no cotidiano apresenta uma dinamicidade muito maior.

O casamento, principal instituição com normas pré estabelecidas, contribui para difundir a ideia de diferença nos papéis sobrepostos ao masculino e feminino. Bassanezi salienta a visão do que socialmente seria uma união perfeita ao destacar atribuições e direitos imputados as categorias mencionadas. Apresenta que:

O casamento-modelo definia atribuições e direitos distintos para homens e mulheres. Tarefas domésticas como cozinhar, lavar, passar, cuidar dos filhos e limpar a casa eram consideradas deveres exclusivamente femininos. Dentro de casa, os homens deveriam ser solicitados apenas a fazer pequenos reparos (2007, p. 626).

A autoridade pertencia em primeiro lugar ao homem que durante a década de 50 segundo a autora, estava respaldado em lei: "A sociedade conjugal pressupunha uma hierarquia, respaldada pela legislação, em que o marido era o chefe, detentor de poder sobre a esposa e os filhos, a quem cabiam as decisões supremas, a última palavra. Logo abaixo vinha a autoridade da esposa" (BASSANEZI, 2007, p. 626).

No que tange ao relacionamento dos casais pobres a ausência de propriedades e as burocracias impostas pelo sistema judiciário constituía entraves para o processo do casamento formal (SOIHET, RACHEL, 1997, p. 368). Predominantemente nesta camada social as altas taxas de uniões estáveis e instáveis permanecem até os dias de hoje. Conforme a mesma autora: "O alto custo das despesas matrimonias era mais (sic) um dos fatores que levavam as camadas mais pobres da população a viver em regime de concubinato”. Não havendo despesas para a realização do ato matrimonial consequentemente não haveria despesas para a separação ou divórcio. 
Um dos itens que causava as separações durante os fins do século XIX começo do XX, estava relacionado à subalternidade dessa mulher ao seu companheiro, Soihet descreve que:

O estereótipo do marido dominador e da mulher submissa, próprio da família da classe dominante, não aparece se aplicar in totum nas camadas subalternas. Muitas mulheres assumiam um comportamento negador de tal pressuposto. Algumas reagiam à violência, outras recusavam-se a suportar situações humilhantes chegando mesmo a abrir mão do matrimônio - instituição altamente valorizada para a mulher, na época. As condições concretas de existência dessas mulheres, com base no exercício do trabalho e partilhando com seus companheiros da luta pela sobrevivência, contribuíram para o desenvolvimento de um forte sentimento de auto-respeito. Isso lhes possibilitou reivindicar uma relação mais assimétrica, ao contrário dos estereótipos vigentes acerca da relação homem/mulher que previam a subordinação feminina e a aceitação passiva dos percalços provenientes da vida em comum (p. 377).

A não aceitação de determinadas atitudes e comportamentos dos homens, em particular seus companheiros levavam a categoria feminina na situação de pobreza a se revoltar contra a própria relação, e romper se achasse necessário.

A mulher na visão burguesa da sociedade era - e permanece - vista como um ser responsável pela educação dos filhos o cuidado ao marido e a casa. Todavia, na atual conjuntura como no passado, a mulher pobre sempre executou atividades para além da esfera doméstica. Logo em pleno século XXI a situação não mudou para mulheres e homens das camadas economicamente mais baixa da sociedade, pois alguns homens fora do mercado de trabalho continuam vulneráveis ao alcoolismo, a drogas, à violência de vários tipos, depressão etc. o que de certo modo eleva mais a condição de pobreza no dia a dia desses homens, causando novas demandas de políticas públicas.

Essas executam em boa parte de suas ações a perspectiva de gênero tendo como foco a mulher. Não procuramos detalhar as variedades de políticas assim existentes em nosso País, mas situaremos as ações do Programa Bolsa Família Federal como modelo. 
Com o intuito de erradicar a pobreza do País o Programa Bolsa Família transfere renda direta às famílias em situação de pobreza e extrema pobreza a nível nacional, no entanto percebe-se que a maior parte dos titulares que obtém os benefícios são as mulheres que são mães.

$\mathrm{Na}$ cidade de Manaus a amplitude das pessoas na condição de titularidade que auferem o Bolsa Família é de 89.246, dentre elas 6.091 são homens, ${ }^{3}$ representando apenas $6,82 \%$. Os números divulgam que há um público alvo para a retirada do subsídio - a mulher -, todavia Cunha enfatiza: [...] além de ter a família como alvo de sua ação, o PBF reconhece e reforça a importância das mulheres na família. Ela é responsável legal e preferencial para o recebimento dos benefícios, situação que está presente em 95\% das famílias beneficiárias (2007, p. 10).

A isso segue-se uma linha de pensamento em relação a mulher atribuindo a ela: responsabilidade para com a família e a criação dos filhos, saber administrar o recurso com equidade, somados ao alto número de famílias monoparentais chefiadas pela categoria, são bases que até mesmo servem de proposta para as políticas públicas de combate à pobreza no Brasil.

Uma análise mais aprofundada sobre o papel das mulheres nas propostas de políticas públicas de combate à pobreza no contexto do neoliberalismo e o papel assistencial das mulheres no âmbito da família, tanto nas abordagens neoliberais como no chamado Estado providência, mostra a dimensão política presente na relação público-privado (CARLOTO, 2006, p. 142).

Apesar do PBF ter uma proposta inovadora pelo fato de reconhecer a mulher como chefe de família, ele acaba reforçando a gestão de gênero, pois nessa reforça-se a ideia da mulher sendo boa mãe e em contraponto ele passa uma ótica do homem ainda como único provedor, que somado a anulação do masculino da situação de titularidade, estereotipa-o.

\section{A família monoparental chefiada pelo homem e as relações de gênero na cidade de manaus}

Segundo alguns autores, a família é a principal instituição de sociabilidade 
do indivíduo e, por meio dela se aprende e é transpassada a cultura de uma sociedade, afetos e cuidados. No seu bojo há variadas configurações, não há um modelo único de família, ela pode ser nuclear, extensiva, reconstituída e monoparental, sendo que nessa uma só pessoa é responsável pelo comprimento dos papéis tanto do masculino, quanto do feminino na relação com seus membros, Kalostian retrata bem o mosaico dos arranjos familiares quando se refere:

A família, da forma como vem se modificando e estruturando nos últimos tempos, impossibilita identificá-la como um modelo único ideal. Pelo contrário, ela se manifesta como um conjunto de trajetórias individuais que se expressam em arranjos diversificados e em espaços e organizações domiciliares peculiares (2000: p. 14).

No Brasil dentre esses moldes de famílias hegemonicamente aparece a de formação monoparental chefiadas por mulheres, embora o modelo predominante na sociedade seja o da classe burguesa - família nuclear - em volta dos estratos sociais especificamente nas famílias populares não se encontra uma homogeneização dos papéis estipulados para o masculino e feminino. As características dos papéis e dos padrões familiares vêm se desenhando desde o século XIX, emergidos da Europa como mostra Fonseca:

A nova visão da família tornou-se brasão da burguesia, legitimando uma distinção que se alastrava das sensibilidades para vida material. A organização familiar dos grupos populares seguiu uma linha de evolução diferente. A enorme variedade de costumes que caracterizava a Europa prémoderna diminui a partir da Revolução Industrial. Em torno dessa época, é possível identificar certas tendências em todo o subcontinente: casamentos "precoces", um aumento da proporção de uniões consensuais, frequentemente instáveis, e taxa alta de bastardia e crianças em circulação (2007, p. 521).

Há um elevado número de famílias monoparentais dentro do Programa Bolsa Família, que de acordo com a premissa de políticas públicas de combate à pobreza, valoriza a família como local privilegiado de superação das sequelas da questão social, priorizando as mulheres por seu papel de mãe, o PBF escolhe as 
mesmas para condição de titularidade do repasse da transferência direta de renda as famílias em situação de vulnerabilidades socioeconômica. Por família, segundo os critérios do Programa entende-se: como a unidade nuclear, eventualmente ampliada por pessoas que com ela possuam laços de parentesco ou de afinidade, que forme um grupo doméstico, vivendo sob o mesmo teto e que se mantém pela contribuição dos membros (CUNHA, 2007, p. 5).

Existem casos de abandonos relacionados às mulheres. Estas saem de casa deixando para trás o cônjuge e os filhos, resultando nas famílias monoparentais chefiadas pelos homens. Isso ainda não se tornou número alto, mas alguns casos foram descobertos dentro do Programa Bolsa Família nos quais por meio de pesquisa realizada na Central do Programa em Manaus pelos questionários aplicados com esses homens nos propomos elucidar.

A priori abordamos como esses, pais, chefes de família monoparental se que encontravam no mercado de trabalho. Os resultados revelam as condições de trabalho dos entrevistados: $70 \%$ deles responderam que exercem algum tipo de trabalho, 30\% não trabalhavam, isto é, viviam de ajuda e, dos que trabalhavam somente $36 \%$ afirmaram que era de carteira assinada.

O retrato da situação de vários brasileiros, no qual o mercado de trabalho interfere diretamente na figura do homem ser ou não provedor do lar, demonstra a precariedade da categoria - trabalho - , que desde o século XIX, mostra sua face no que tange ao homem, segundo Fonseca, o mercado de trabalho masculino assim constituia-se: "O homem podia até ser "trabalhador" - quem garantia que ia ter uma renda regular? Havia competição para os bons empregos. Uma vez recrutado, o homem não tinha garantia de estabilidade: (...), corria os perigos de doença ou demissão" (1997, p. 516),

Atualmente o essencial meio de sobrevivência para todos encontra-se subdividido entre formalidade e informalidade, pois o emprego perdeu sua característica de estabilidade, e muitos direitos adquiridos com lutas e mortes dos proletariados ficaram relegados através dos reajustes do sistema trabalhista, tendo como resultado desmontes nas garantias adquiridas no decorrer dos séculos elevando a precariedade das relações do trabalho que aumentam durante as crises econômicas.

A terceirização tomou para si - ou lançaram para ela - o compromisso das contratações tanto que nas empresas, indústrias do capital e parte de alguns funcionários dos órgãos públicos, nos últimos anos a informalidade e subcontratações efetivaram-se com força total lançando vários sujeitos chefes 
ou não de família ao descaso do mercado, este totalmente neoliberal preconiza a individualização, polivalência e a competitividade entre os indivíduos, ideologicamente pondo a vítima na condição de culpada.

Toda a questão que circunscreve a categoria emprego nos dias atuais reflete nos membros das famílias, que juntamente com o responsável de prover o lar sofrem as vicissitudes do mercado de trabalho na esfera da economia familiar, lançando então várias famílias a dependerem de programas de transferência de renda como o Bolsa Família. Dessa forma, consoante o panorama dos dados coletados a respeito da situação do número de membros por moradia que dependem do Programa pode-se depreender que essas famílias monoparentais chefiadas pelos homens, com a estimativa de $45 \%$ no seu domicilio é composto de dois a quatro membros, bem abaixo com pouca diferença, as famílias de cinco a sete membros num percentual de $40 \%$. Sendo que o número maior da estrutura familiar é formado por crianças nos dois casos.

Todavia para o PBF não importa se algum membro da família trabalhe de carteira assinada, desde que, não ultrapasse a renda per capita de $\mathrm{R} \$ 137,00$ ele foi criado para favorecer as famílias mais pobres e assegurar o direito à alimentação. Porém, vários relatos tanto de homens, quanto de mulheres, aqui em especial os homens, alegam que o beneficio também é gasto com a educação ficando com uma estimativa de 40\%, seja na compra de material escolar ou nos pagamentos das passagens de ônibus para as crianças irem à escola. Os gastos pessoais aparecem com 25\% correspondendo a materiais de higiene pessoal, ou até mesmo o gasto dos pais em coisas pessoais sem o repasse as crianças.

Identificamos que há pouca diferença das ex-cônjuges que trabalhavam fora quando ocorreu a separação, próximo de 55\% trabalhavam, em contrapartida de $45 \%$ das que não trabalhavam e, isso revela que a mulher rompe o vínculo mesmo não estando atuando na esfera pública como, por exemplo, no mercado de trabalho.

A dificuldade na criação dos filhos dentro das famílias monoparentais masculinas ou femininas, está mais especificamente relacionada ao cumprimento dos dois papéis por uma só pessoa, pois acredita-se que a família é essencialmente responsável pela alimentação e pela proteção da criança, da infância à adolescência. Pois de acordo com Kaloustian, (2000: p. 5) "A iniciação das crianças na cultura, nos valores e nas normas de sua sociedade começa na família".

As poucas informações que os homens/pais têm a respeito do Programa 
Bolsa Família, está relacionado ao fato de sua ex-cônjuge ser anteriormente a titular do beneficio, e tudo referido ao mesmo ser tratado com ela, constatamos que quase a metade dos pais não conheciam as condições para permanecerem no Programa.

Sobre as condicionalidades Cunha esclarece:

As condicionalidades, na concepção adotada pelo Bolsa Família, podem ainda ser entendidas como um contrato pautado por três tipos de responsabilidade complementares. De um lado, são responsabilidades das famílias em relação ao cumprimento de uma agenda mínima na área da saúde e da educação que possam melhorar as condições, para que as crianças e os jovens de famílias beneficiarias desfrutem de maior bem-estar no futuro (2007, p. 7).

A diferença é bem pequena dos que conheciam ou não as condicionalidades, o que é alarmante, pois a eventualidade do pagamento dos benefícios depende do cumprimento delas. A informação é importante, pois ela é um grande mecanismo que leva indivíduos à conquista de seus direitos na condição de cidadãos de um País, Estado ou Nação. Principalmente daqueles que se encontram nas camadas econômicas mais baixas de determinada sociedade, amparados ou não por Programas Sociais.

Embora seja difícil cumprir com as responsabilidades, cerca de $65 \%$ afirmaram que mesmo sozinhos conseguem suprir as necessidades dos filhos. Isso resulta em novas formas de masculinidade como aponta Siqueira: "A constituição de novas masculinidades acompanha as novas paternidades, uma vez que o que está em des-construção é o modelo tradicional de gênero, ou seja de ser homem e mulher" (1999, p. 194), e 35\% responderam não conseguir suprir as necessidades de suas crianças.

A maioria dos entrevistados responderam que permaneciam solteiros desde o rompimento, sendo que poucos foram os que disseram que queriam unir-se de novo a alguém. Em torno de $20 \%$, porque segundo eles precisam de uma mulher para ajudar na criação de seus filhos.

No que se refere à má reputação imposta culturalmente de mulher separada e de mães que abandonam os filhos, confirma-se que esta imagem não influenciou na decisão das mulheres, pois, embora o índice de rompimentos serem maiores entre as camadas populares, no início do século XX, as mulheres 
separadas e recasadas eram discriminadas, e sua condição de classe não importava socialmente, consoante Lavau (1995: p.80): "Somente (sic) no final do período que vai de 1967 a 1992, as mulheres tinham obtido assim o direito a dispor do seu corpo, a escolher a sua vida sexual, o que lhes permite, num domínio mais vasto, disporem de si próprias...". Notamos que as mudanças não param deste então, mas a decisão de abandono dessas mulheres renegando o papel de mãe e esposa ainda causam estranhamento quando levamos em conta o sentimento maternal. Percebemos que para a maior parte das mulheres não é fácil abrir mão dos filhos, para outras o mesmo sentimento é algo sem muita intensidade.

Detectamos que a responsabilidade de ser mãe e esposa não tem muita importância para certas mulheres; $60 \%$ delas de acordo com a visão masculina dos entrevistados não repassavam ou o faziam de forma esporádica o benefício para as crianças e, isto deixa transparecer as difíceis circunstâncias dos primeiros meses de abandono.

A premissa das mulheres serem as eleitas para condição de titularidade do beneficio, vem exatamente da condição de ser consideradas mais responsáveis que os homens na criação e alocação do benefício para os filhos, uma vez que estes são os argumentos utilizados pelo MDS, para justificar sua escolha.

Podemos afirmar que essa conclusão parte do princípio que não só as mulheres são mais confiáveis sendo mães, como são mais confiáveis que os homens na utilização correta do benefício e tão ou mais capazes do que eles, para garantir a eficácia dos programas. Mas, os diagnósticos expõem que em algumas realidades a situação é de abandono e utilização do dinheiro em proveito de si, por parte das mães.

A respeito do relacionamento do ex-casal, boa parte dos homens responderam que as "amizades" delas contribuíram com o final do relacionamento e, muitos deles mencionaram as amizades que elas tinham no trabalho ou até mesmo de vizinhos.

Logo em seguida aparecem as brigas do casal como uma das causas, muitos citaram que o fato de não estarem trabalhando e por isto não conseguir manter o sustento da casa. Esse fato foi na grande maioria o motivo de brigas constantes acompanhadas de certas humilhações por parte das companheiras. Consequentemente percebe-se que mesmo as mulheres recebendo o benefício elas querem que o homem cumpra com o papel de provedor. 
Além das influências das amizades e as brigas do casal, o trabalhar fora de casa, o conhecer outros homens, o querer ter mais liberdade estão em quantidades expressivas nas respostas. Siqueira demonstra bem essa realidade ao afirmar que as mulheres atuais:

Lutam pelos seus direitos civis, lutam pelo seu direito de escolha, lutam pelo seu direito à sexualidade e ao prazer, enfim, há todo um contingente de mulheres neste momento que não encontram em suas mães ou avós um modelo de identificação. Buscam a construção de um novo jeito de ser mulher. Certamente este processo não é linear, harmonioso, isento de conflitos e contradições. Tratamse, no entanto, possivelmente de transformações em curso (1999, p. 191).

Dentre os tipos de uniões entre homens e mulheres nas camadas populares prevalece as de forma estáve. Esses números divulgam que preponderam costumes do passado relacionado às uniões conjugais, conforme demonstra Fonseca, durante o decorrer do século XX:

Muitos casais dispensavam o casamento legal; divórcios eram raros [...]. Com o exame cuidadoso dos processos jurídicos, vislumbramos uma sociedade de pessoas que se esquivavam aos controles legais: juntavam-se sem casar, pariam filhos sem fazer certidões de nascimento, separavam-se sem fazer divórcio (1997, p. 522 e 523).

Tais fatos ainda permanecem nos grupos de baixa renda, e neles, encontramos vários casos dentro do Programa Bolsa Família, que tornouse em um instrumento vasto de fonte de informação já que a realidade das famílias mudam com constância.

\section{Considerações finais}

Nos estudos de gênero ainda prevalece a figura da mulher como o principal objeto analisado, e poucos se relacionam ao homem. Quando o 
fazem estes ainda estão ligados à figura do tipo burguês, provedor, dominador, detentor do poder. Há, portanto uma camada frágil dos homens na sociedade, que estão expostos à pobreza, à falta de emprego e as cobranças culturais que o envolve.

As políticas públicas atuais reconhecem a mulher como a principal categoria para implantação de seus serviços, especificando-os. Essa percepção de gênero focalizante - favorece a mulher por achar-se que ela é mais responsável pelo bom andamento do lar e a criação de seus filhos -, e relega ainda mais o papel masculino a provedor, e por que não dizer, ausente do espaço privado.

Percebemos, portanto, na tessitura do cotidiano, mulheres que abandonam os filhos e o lar, contrariando a norma estabelecida e as políticas públicas decorrentes. Relatos de abandono da esposa e mãe chegam à Central do Bolsa Família em Manaus, por parte do pai. Muitos afirmaram que a mãe não repassavam o benefício para os filhos, motivo que os levaram a Central pedindo a mudança de titularidade do pagamento para o nome deles.

O caso de famílias monoparentais chefiadas pelos homens no Brasil ainda não alcançou patamares elevados como das que são formadas por mulheres, porém os números podem crescer no decorrer dos anos, requerendo políticas voltadas para esse campo.

A monoparentalidade tem números altos nas camadas mais populares. Os vínculos conjugais nesta classe são frágeis. Percebemos que fatores econômicos e culturais são preponderantes para continuidade dos relacionamentos, onde há índice de uniões instáveis que reflete novos arranjos familiares como os monoparentais e famílias reconstituídas. Os valores e condutas burgueses dos papéis estabelecidos para homens e mulheres não são de fácil adesão nas camadas populares, e isso traduz no desempenhar dos papéis novas formas de masculinidade e feminilidade, masculinidade e paternidade.

Por fim, diante de tudo isso pensar em políticas públicas voltando-se somente para a categoria de gênero, corre-se o risco de excluir e marginalizar indivíduos. Somada a realidade de gênero deve estar a de classe, etnia, geração e as construções culturais locais dos papéis sociais.

\section{Notas}

${ }^{1}$ Mestre em História pela Universidade Federal do Rio Grande do Sul - UFRGS, professora 
da Faculdade Salesiana Dom Bosco (FSDB) e do Centro Universitário do Norte (Uninorte).

${ }^{2}$ www. noruega.org.br/policy/gender/male/male.htm. Acesso em: 24/4/2008.

${ }^{3}$ Dados extraídos da folha de pagamento do mês de novembro de 2008.

\section{Referências}

BASSANEZI, Carla. História das mulheres no Brasil. In. Mulheres dos anos dourados. Mary Del Priore (org.); Carla Bassanezi (coord. de texto) 9. ed. - São Paulo: Contexto, 2007.

BRASIL, Ministério da Saúde. Secretaria de Atenção à Saúde. Departamento de Ações Programáticas Estratégicas. Política nacional de atenção integral à saúde da mulher:princípios e diretrižes / Ministério da Saúde, Secretaria de Atenção à Saúde, Departamento de Ações Programáticas Estratégicas. - Brasília: Ministério da Saúde, 2004. 82 p.: il. - (C. Projetos, Programas e Relatórios)

CARLOTO, Cássia Maria. Gênero, políticas públicas e centralidade na família. Revista Serviço Social e Sociedade, Ano XXVII, julho, 2006. no 86. Editora Cortez.

CUNHA, Rosani. Transferência de Renda com Condicionalidade: A experiência do Programa Bolsa Família. Texto elaborado como subsídio ao "Curso para directivos: transferências condicionadas”. Brasília: Indes/BID, jul. 2007.

Familia brasileira, a base de tudo/Sílvio Manoug Kaloustian (organizador). 4. ed. São Paulo: Cortez; Brasília, DF: Unicef, 2000.

FARAH, Marta Ferreira Santos. Gênero e políticas públicas. <http:// www.scielo. br/pdf/ref/v12n1/21692.pdf> Acesso em: 14/9/2008.

FONSECA, Cláudia. História das mulheres no Brasil. In: Ser mulher, mãe e pobre. Mary Del Priore (org.); Carla Bassanezi (coord. de texto) 9. ed. - São Paulo: Contexto, 2007.

FURASTÉ, Pedro Augusto. Normas Técnicas para o trabalho cientifico, que todo mundo pode saber, inclusive você: Explicitação das Normas da ABNT. - II. ed. - Porto Alegre: s.n., 2002.

HAMAWI, Rodolfo. Que querem os homens? A Desconstrução do Masculino NOLASCO, Sócrates (Org.). Rio de Janeiro: Rocco, 1995.

LAVAU, Janine Mossuz. As mulheres e a história. In. As mulheres e a sexualidade: novos direitos, novos poderes? DUBY, Georges e PERROT, Michelle. (org.). Tradução de Miguel Serras Pereira. Lisboa: Publicações Dom Quixote, 1995. 
LOURO, Guacira Lopes. História das mulheres no Brasil. In.Mulheres na sala de aula. Mary Del Priore (org.); Carla Bassanezi (coord. de texto) 9. ed. - São Paulo: Contexto, 2007.

RAGO, Margareth. História das mulheres no Brasil. In. Trabalho feminino e sexualidade. Mary Del Priore (org.); Carla Bassanezi (coord. de texto) 9. ed. São Paulo: Contexto, 2007.

RODRIGUES, Aroldo. Psicologia Social para principiantes. Editora Vozes - Rio de Janeiro, 1992.

SIQUEIRA, Maria Juracy Tornelli. Falas de gênero: Teorias, análises, leituras. In. Novas formas de paternidade: repensando a função paterna à luz das práticas sociais. /organizado por Alcione Leite da Silva, Mara Coelho de Souza Lago e Tânia Regina Oliveira Ramos - Florianópolis: Editora Mulheres, 1999

SOIHET, Raquel. História das mulheres no Brasil. In. Mulheres pobres e violência no Brasil Urbano. PRIORE, Mary Del (org.). São Paulo: Unesp/Contexto, 1997. <http://www.mds.gov.br/institucional/secretarias/secretaria-de-avaliacao-egestao-da-informacao-sagi/pesquisas $>$ Acesso em: 17/03/2008.

$<$ http://www.cchla.ufpb.br/caos/06-deleon.html> Acesso em 24/04/2008. $<$ bvsms.saude.gov.br/bvs/publicacoes/politica_nac_atencao_mulher.pdf $>$ Acesso em: 5/5/2008

$<$ www.mds.gov.br> Acesso em: 8/5/2008

$<$ www.caixa.gov.br > Acesso em: 8/5/2008

$<$ http://www.mds.gov.br/noticias/pesquisa-constata-que-bolsa-familia$\mathrm{da}$-mais-autonomia-as-mulheres $/$ ? searchter $\mathrm{m}=$ avaliaca $\% 20 \mathrm{do} \% 20$ programa\%20bolsa\%20familia > Acesso em: 8/5/2008

<http://www.planalto.gov.br/ccivil_03/_Ato2004-2006/2004/Lei/L10.835. $\mathrm{htm}>$ Acesso em: 12/11/2008.

<http://www.mds.gov.br/bolsafamilia/o_programa_bolsa_familia/oque-e/> Acesso em: 15/11/2008. 